\title{
Chromosome Breaks and Gaps in Breast Cancer Patient
}

\author{
S. A. Husain ${ }^{1}$, S. Balasubramanian ${ }^{2}$ and R. Bamezai ${ }^{3}$ \\ ${ }^{1}$ Centre for Biosciences, Jamia Millia Islamia, New Delhi-110025, India \\ ${ }^{2}$ Department of Anatomy, Institute of Medical Science, Banaras Hindu University, \\ Varansi. U.P, 221005, India \\ ${ }^{3}$ School of Life Sciences, Jawaharlal Nehru University, New Delhi, 110067, India
}

Accepted November 24, 1995

Breast cancer is the most frequent tumour among of western countries women, (Sandberg 1990). In India, it is the second most common cancer. The rate per 100,000 of breast cancer is 20.2 (Jussawala 1973). This malignancy can be divided into various stages as follows (Walter and Israel 1987):

Stage I The tumour were confined to the breast including the skin immediately over it.

Stage II Tumour involved the axillary lymph nodes on the same side, but both breast and nodes are mobile.

Stage III Tumour spread to the chest wall on the supra claviclar nodes on the same side.

Stage IV More spread then stage III and included blood borne metastases.

There are various studies where chromosomal changes were seen as an important feature responsible for this cancer (Cruciger et al. 1976, Pathak 1980, Gebhart et al. 1986, Pandis et al. 1993, Thompson et al. 1993, Hainsworth et al. 1991, Rohen et al. 1995) and also some form of genetics instability of an individual might be a predisposing factor (Atkin 1976, German 1974).

In the present study we report the significant higher rate of chromosomal breaks and gaps in the lymphocyte of stage II breast cancer cases as compared to other next stages and their normal controls.

\section{Material and methods}

Peripheral blood (PB) was collected from 15 patients with breast cancer ( 3 stage II, 8 stage II and 4 stage IV). Five normal women were also studied as age matched controls. Smokers, alcoholics and patients taking any kinds of drug were excluded from this study. The intra-veinous blood was collected at $9.00 \mathrm{am}$. and cultures were put at $10.00 \mathrm{am}$.

Whole blood cultures were set up by conventional method (Husain and Bamezai 1988) i.e., $0.2 \mathrm{ml}$ of heparinized whole blood was added to $6.00 \mathrm{ml}$ RPMI-1640 medium (Bios, Bombay, India) in a sterile culture bottle under asceptic conditions. To this $0.3 \mathrm{ml}$ of phytohemagglutinin-M (PHA-M, Gibco) was added and the cultures was shaken and incubated at $37^{\circ} \mathrm{C}$ for 72 hr. Colchicine $(0.2 \mathrm{ml}-10 \mu 1 / \mathrm{ml}$, Bios $)$ was added at $68 \mathrm{hr}$ i.e., at $4 \mathrm{hr}$ before termination of the cultures to arrest the cells at metaphase, because $4 \mathrm{hr}$ exposure in our system gives better results. The cultures were harvested at $72 \mathrm{hr}$ and slides were prepared by routine procedures, and stained with Giemsa stain (Watt and Stephen 1986) and slides were observed under the microscope. The same slides were observed by two persons to confirm the breaks and gaps.

Only chromosomal breaks and gaps were scored according to the criteria laid down by ISCN (1985) which is as follows:

Correspondent Author: S. A. Husain, Centre for Biosciences, Jamia Millia Islamia (Central University) New Delhi-110025, India. 

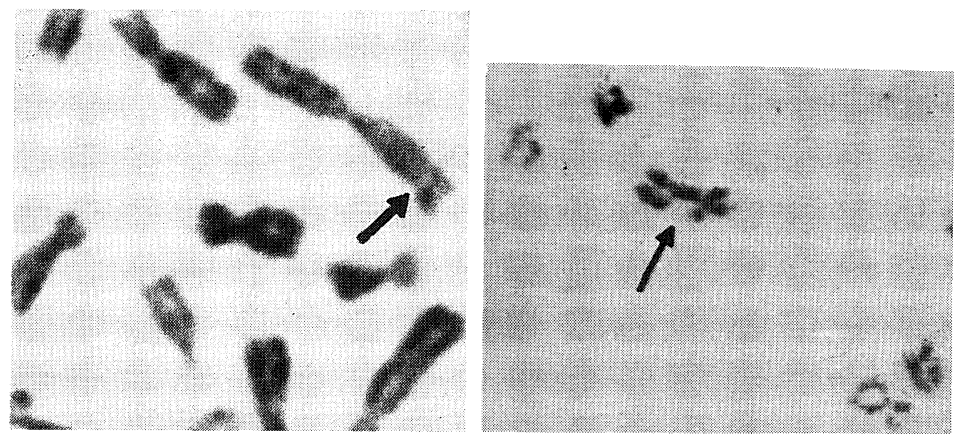

Fig. 1. Partial Photograph respresenting with arrow; Chromosome gap (left); only chromatid break (right).

Table 1. Average rates of chromosome gaps and breaks occuring/cell in lymphocytes of patients with various stages of breast cancers and their normal controls

\begin{tabular}{|c|c|c|c|}
\hline $\begin{array}{c}\text { S. } \\
\text { No. }\end{array}$ & Subject & $\begin{array}{c}\text { Total } \\
\text { no. }\end{array}$ & $\begin{array}{l}\text { Average rate of } \\
\text { chromosome gaps } \\
\text { and breaks. }\end{array}$ \\
\hline
\end{tabular}

1. Breast cancer

$\begin{array}{lll}\text { (a) Stage II } & 3 & 1.61 \\ \text { (b) Stage III } & 8 & 1.04 \\ \text { (c) Stage IV } & 4 & 1.20 \\ \text { Normal Controls } & 5 & 1.36\end{array}$

$G A P$

Chromatid gap (ctg) Chromatid gap is a non-staining region (achromatic lesion) of a single chromatid in which there is a minimum misalignment of the chromatid.

Chromosome gap (csg) Chromosome gap is a non-staining region (achromatic lesion) at the same locus in both chromatids of a single chromosome in which there is minimal misalignment of the chromatid (Fig. 1-left).

\section{BREAK}

Chromatid break (ctb) Chromatid break is a discontinuity of a single chromatid in which there is a clear misalignment of one of the chromatids (Fig. 1-right).

Chromosome break (csb) Chromosome break is a discontinuity at the same locus in both chromatids of a fragment and an abnormal monocentric chromosome.

Because no significant difference was observed between breaks and gaps so the data of breaks and gaps was clubbed together.

The Chi-square test was applied to find out any significant difference (Snedecor and Cochrain 1980) between the patients of different groups and normal control and among patients themselves.

\section{Results}

Table 1 depicts the average rate of occurrence of chromosome gaps and breaks which were $1.61,1.04$ and 1.20 in stage II, II and IV, respectively of breast cancer cases and 1.36 in normal controls.

Table 2 presents the complete data of breaks and gaps of each individual case.

Apparently the incidence of spontaneous chromosomal aberrations i.e., breaks and gaps were higher in stage II breast cancer case.

The statistical analysis showed a significant difference in the incidence of chromosomal gaps and breaks when comparison were made between total cancer cases and normal control $(\mathbf{P}<0.05)$, stage II breast cancer cases and normal controls $(\mathbf{P}<0.001)$, stage II breast cancer cases and stage III breast cancer cases $(\mathrm{P}<0.05)$. 
Table 2. Cancer cases alongwith normal control having chromosomal gaps and breaks as well as metaphase plates with chromosomal gaps and breaks

\begin{tabular}{|c|c|c|c|c|c|c|c|c|c|c|c|}
\hline \multirow[t]{2}{*}{$\begin{array}{c}\text { S. } \\
\text { No. }\end{array}$} & \multirow[t]{2}{*}{ Subjects } & \multirow[t]{2}{*}{$\begin{array}{c}\text { Stage of } \\
\text { Cancer }\end{array}$} & \multirow[t]{2}{*}{$\begin{array}{c}\text { Patient } \\
\text { No. }\end{array}$} & \multirow[t]{2}{*}{$\begin{array}{l}\text { Total no. of } \\
\text { cases with gaps } \\
\text { and breaks } \\
\text { studied }\end{array}$} & \multirow[t]{2}{*}{$\begin{array}{c}\text { Total } \\
\text { cell } \\
\text { scored }\end{array}$} & \multicolumn{5}{|c|}{$\begin{array}{l}\text { Chromosome Gaps } \\
\text { and breaks in } \\
\text { chromosome breaks } \\
\text { Groups }\end{array}$} & \multirow[t]{2}{*}{$\begin{array}{c}\text { Total gaps } \\
\text { breaks } \\
\text { scored }\end{array}$} \\
\hline & & & & & & A & B & $\mathrm{C}$ & $\mathrm{D}$ & $\mathrm{E}$ & \\
\hline \multirow[t]{18}{*}{1} & Breast Cancer & (a) Stage II & GC-4 & & 16 & 4 & 4 & 7 & 2 & & 17 \\
\hline & & & GC-12 & & 1 & - & - & 1 & - & - & 1 \\
\hline & & & GC-34 & & 49 & 15 & 11 & 35 & 25 & 2 & 88 \\
\hline & & & & 3 & 66 & 19 & 15 & 43 & 27 & 2 & 106 \\
\hline & & (b) Stage III & GC-28 & & 13 & 4 & 4 & 4 & 2 & 1 & 15 \\
\hline & & & GC-29 & & 1 & - & - & 1 & - & - & 1 \\
\hline & & & GC-31 & & 14 & 3 & 3 & 4 & - & 1 & 11 \\
\hline & & & GC-35 & & 2 & 1 & 1 & - & - & - & 2 \\
\hline & & & GC-56 & & 11 & 3 & 1 & 5 & 1 & 1 & 11 \\
\hline & & & GC-64 & & 3 & 1 & - & 1 & 1 & - & 3 \\
\hline & & & GC-79 & & 1 & - & - & 1 & - & - & 1 \\
\hline & & & GC-84 & & 3 & 2 & - & 1 & - & - & 3 \\
\hline & & & & 8 & 45 & 14 & 9 & 17 & 4 & 3 & 47 \\
\hline & & (c) Stage IV & GC-36 & & 2 & 1 & - & 2 & - & - & 3 \\
\hline & & & GC-50 & & 6 & 1 & 3 & 2 & - & - & 6 \\
\hline & & & GC-58 & & 6 & 1 & 2 & 3 & 2 & - & 8 \\
\hline & & & GC-75 & & 1 & 1 & - & - & - & - & 1 \\
\hline & & & & 4 & 15 & 4 & 5 & 7 & 2 & - & 18 \\
\hline \multicolumn{12}{|c|}{ 2. Normal Control } \\
\hline & 1 & & & & 36 & 23 & 9 & 20 & 3 & - & 55 \\
\hline & 2 & & & & 1 & - & - & 01 & - & - & 1 \\
\hline & 3 & & & & 10 & 3 & 1 & 7 & - & - & 11 \\
\hline & 4 & & & & 1 & - & - & 1 & - & - & 1 \\
\hline & 5 & & & & 08 & 2 & 2 & 2 & 2 & - & 8 \\
\hline & & & & 5 & 56 & 28 & 12 & 31 & 5 & & 76 \\
\hline
\end{tabular}

\section{Discussions}

So far as sufficient literature is not available about the spontaneous chromosomal aberrations such as gaps and breaks in stage specific breast cancer cases. In the present investigation we observe that the rate of breaks and gap in stage II breast cancer is significantly higher as compared to stage III and IV breast cancer cases and normal control in lymphocytes.

An increased frequency of chromosomal aberrations in lymphocytes of patients with various cancers such as retinoblastoma (Czeizel et al. 1974, de Nunez et al. 1984), renal carcinoma (Wang et al. 1982), Cervix cancer (Murthy et al. 1985) and many other cancer has already been reported. Although, there is no such report in breast cancer cases. The frequencies of gaps is chromosomes have previously been observed to double in patients as compared to controls (Brown et al. 1985). It has also been suggested that the chromosome instability leads to breaks occuring at many different locations which increase the chances of damage and could activate an oncogene to initiate to build up of a clone with the chromosome rearrangement that triggered the neoplastic transformation (Brown et al. 1985).

The present study suggests that the chromosomes breaks and gaps be one of the primary events of the chromosomal instability. However, the biological meaning of the chromosomal 
instability in the development and progression remains unclear (German 1980).

The increased frequency of spontaneous chromosomal aberrations in stage II breast cancer in the present investigation thus may indicate that during the stage II of breast cancer the factors searched by neoplastic cells exerts more pressure for the higher number of breaks and gaps which help in the alteration of chromosomes. However, in the next stage probably there are no much gaps and breaks because altered chromosomes are already stable to produce the required factors for growth of malignant tissues, but this needs an extensive study of breast cancer cases.

\section{Summary}

Chromosomal aberrations such as gaps and breaks were studied in 15 cases of breast cancers (i.e., stage II- 3 cases, stage III- 8 cases and stage IV-4 cases) and their 5 normal age and sex-matched controls.

The average rate of chromosome gaps and breaks were $1.61,1.04$ and 1.20 in stage II, III and IV breast cancer cases respectively, and 1.36 normal age and sex-matched control.

Chi-square comparison showed a significant difference between total breast cancer patients and normal controls $(\mathrm{P}<0.05)$, a higher difference between stage II breast cancer cases and normal control $(\mathrm{P}<0.01)$ and slightly higher difference between stage II and stage III breast cancer cases $(\mathrm{P}<0.05)$.

The result so obtained clearly indicate that probably stage II breast cancer is a crucial stage for maximum chromosomal alteration in this malignancy.

\section{Acknowledgement}

The authors are grateful to Professor N. N. Khanna, I. M. S., B. H. U., Varanasi, for referring the cases for this study.

\section{References}

Atkin, N. B. 1976. Cytogenetic aspects of malignant transformation. In: Exprimental Biology and Medicine Series Vol. 6A Wolsky, ed. S. Karger, Basel.

Brown, T., Dawson, A. A., McDonald, I. A., Bullock I. and Watt, J. L. 1985. Chromosome damage and SCEs in lymphocyte cultures from patients with 2 primary tumors. Cancer Genet. Cytogenet. 17: 35-42.

Crucigar, Q., Pathak, S. and Cailleau, R. 1976. Human breast carcinomas; marker chromosomes involving 1q in seven cases. Cytogenet. Cell Genet. 17: 231-235.

Czeizel, A., Zzosz, L., Gardonyl, J., Remenar, L. and Ruziscka, P. 1974. Chromosome studies in twelve patients with retinoblastoma. IIumangcnctik 22: 159-166.

de Nunez, M., Panchaszadeh, V. B. and Pimentel, E. 1984. Chromosome fragility in patients with sporadic unilateral retinoblastoma. Cancer Genet. Cytogenet. 11: 139-141.

Gebhart, E., Bruderlein, S., Augustus, M., Siebert, E., Feldner, J. and Schmidt, W. 1986. Cytogenetic studies on human breast carcinomas. Breast Cancer Research Treat. 8: 125-138.

German, J. 1974. Bloom syndrome II. The Prototype of human genetic disorders predisposing to chromosomal instability and cancer. In: Chromosomes and Cancer. J. German ed. Wiley New York. pp. 601-617.

German, J. 1980. Chromosome breakage syndorme: Different genes, different treatments, different cancer In: DNA Repair and Mutagenesis. W. M. Generoso, M. D. Shelbe and F. J. DeSerrer, eds. Plenum, New York, pp. 429-439.

Hainsworth, P. J., Raphael, K. L., Stillwell, R. C., Bannett, R. C. and Garsan, O. M. 1991. Cytogenetic features of twenty siz Primary breast cancer. Cancer Genet. Cytogenet. 52: 205-218.

Husain, S. A. and Bamezai, R. 1988. Sister chromatid exchange (SCE) rate in normal and abrormal sexual development in males and females. Mutat. Res. 206: 261-270.

Jussawala, D. J. 1973. Cancer incidence patterns in the subcontinent of India. Proc. Roy. Society of Medicine 66: 308- 
312.

ISCN 1985. An International system for Human Cytogenetics Nomanclature, Harden D. G., Klinger H. P. (Eds.) Published in collaboration with Cytogenetics and Cell Genetics, Karger, Basel.

Murthy, V. V. V. S., Mitra, A. B. and Luthra U. K. 1985. Spontaneous chromosomal aberrations in patients with Precancerous and Cancerous lesions of the cervix uteri. Cancer. Genet. Cytogenet. 17: 347-354.

Pandis, N., Heim, S., Bardi, G., Idvall, I., Mandahil, N. and mitelman, F. 1993. Chromosome analysis of 20 breast carinomas; cytogenetic multi-clonality and karyotypic-Patholic correlations. Genes Chrom. Cancer 6: 5157.

Pathak, S. 1980. Cytogenetic analysis of human breast tumors. Cancer Genet. Cytogenet. 1: 281-289.

Rohen, C., Meyer-Bolte, K., Bank, U., Ebel, T., Staats, B., Leuschner, E., Gohla, G., Caselitz, J., Bartritzke, S. and Bullerdiak, J. 1995. Trisomy 8 and 18 as frequent clonal and single-cell aberrations in 185 primary breast carcinomas. Cancer Genet. Cytogenet. 80: 33-39.

Sandberg, A. A. 1990. The Chromosome in Human Cancer and Leukemia 2nd Ed. Elsavier, New York.

Snedecor, G. W. and Cochrain, W. G. 1980. Statistical Methods. The lowa State University Press, Arkes, Iowa.

Thompson, F., Emersn, J., Dalton, W., Jin-Ming, Y., Mc Gee, D., Villar, H., Knox, S., Massey, K., Weinstein, R., Bhattacharya, A. and Trent, J. 1993. Clonal chromosome abnormalities in human breast carcinomas 1. Twenty eight cases with primary disease. Genes. Chrom. Cancer 7: 185-193.

Wang, N., Kantor, A., Soldet, L., Linguist, L., Strand, R., McLanghlin, J. and Schuman, L. 1982. Higher frequency of chromosomal aberrations and polymorphism in patients with renal carcinoma. Am. J. Hum. Genet. 34: 78A.

Walter, J. B., Israel, M. S. 1987. Staging of Tumors. General Pathology, VIth Ed. Churchill, Livingstone. Edinburgh London, pp. 393.

Watt, J. L. and Stephen, G. S. 1986. Lymphocyte Culture and chromosome analysis-chapter 2. pp. 49 In Rooney and Czepukowski, Human Cytogenetics - a practical approach, IRL Press, Washington DC, 